\title{
Fish Oll as a Potential Contributor to Epidural Hematoma Following Cervical Epidural Steroid Injection: A Case Report and Focused Literature Review
}

\author{
Eric J. Jenkie, $\mathrm{DO}^{1}$, Ramsin M. Benyamin, $\mathrm{MD}^{2}$, and Laxmaiah Manchikanti, $\mathrm{MD}^{3}$
}

Fish oil has been anecdotally linked to bleeding complications during interventional spinal procedures. We present a case report involving a cervical epidural hematoma following cervical epidural injection in a patient who has been taking fish oil, with detailed literature review.

A 49-year-old woman with a previous history of anterior cervical disc fusion at C5-C6 underwent routine cervical epidural injection for neck pain due to a disc herniation below her fusion. Thirty minutes after the procedure, she experienced numbness and tingling in both arms and developed severe pain between her shoulder blades. She was sent to the emergency room and soon developed a left-sided wrist drop. An emergent cervical magnetic resonance image (MRI) revealed an epidural hematoma at $\mathrm{C} 6-\mathrm{C} 7$. She underwent emergent surgical decompression of the hematoma through multiple laminectomies at C6, C7, and T1. The surgeon noticed excessive blood oozing through the incision site and left two drains in the wound. She recovered without neurological deficit. Upon further investigation, it was discovered that she had been taking high doses of over-the-counter fish oil.

Ingredients in over-the-counter preparations are not regulated or standardized. Fish oil use may predispose a patient to bleeding complications when used in higher doses alone or when used at any dose in conjunction with antiplatelet therapy. The benefits of fish oil use should be weighed against the potential risk of bleeding with cessation of fish oil in patients undergoing spinal interventions. As described by others, significant pain at the site of injection which is unusual and different from the pain experienced in the past as well as complicating factor of loss of resistance technique in closed space must be considered. Finally, rapid diagnosis and intervention avoids neurological deficit.

Key words: Fish oil, omega-3, aspirin, cervical epidural steroid injection, complication, epidural hematoma, literature review
Cardiovascular disease is the leading cause of death globally and in the United States, with heart disease striking someone in the United States about once every 43 seconds with deaths in over 375,000 people per year (1). Similarly, even though not responsible

From : ${ }^{1}$ Advocate Illinois BroMenn Medical Center, Normal, IL; ${ }^{2}$ Millennium Pain Center, Bloomington, IL and University of Illinois, UrbanaChampaign, IL; ${ }^{3}$ Pain Management Center of Paducah, Paducah, KY and University of Louisville, Louisville, KY

Author for correspondence: Ramsin M. Benyamin, MD

Address: Millennium Pain Center, 1015 S. Mercer, Bloomington, IL 61701

E-mail: ramsinbenyamin@yahoo.com for deaths as cardiovascular disorders, chronic pain is highly prevalent leading to significant disability in the United States and across the globe $(2,3)$. The health care and economic impact of both conditions is enormous with numerous modalities of treatments offered to manage cardiovascular disorders, as well as chronic pain. Various modalities of preventive measures utilized in reducing the risk of cardiovascular disease include administration of multiple drugs including aspirin, antithrombotic agents, and omega-3 fatty acids available in the form of fish oil (4-6). Epidural injections are one of the common modalities of treatment in managing spinal pain with reported effectiveness and cost utility (7-16). Conceivably, many 
patients receiving multiple preventive measures, either primary or secondary, including the intake of fish oil, present to interventional pain management settings. Since fish oil or omega fatty acids are nonprescription mediations available over the counter, physicians often miss assessing the risk of fish oil prior to performing interventional techniques. Fish oil has been used extensively with both health professionals, including the American Heart Association (AHA), and the public giving significant attention to the potential health benefits of omega-3 polyunsaturated fatty acids (17-20). Despite these recommendations and purported benefits, multiple risks also have been reported with use of fish oil supplements (4-6,17-28).

Despite the controversial benefits and associated risks, according to the National Institutes of Health $(\mathrm{NIH})$, fish oil has now become the third most widely used supplement in the United States and the AHA continues to recommend it with claims that omega-3 fatty acids decrease the risk of heart arrhythmia, slow down growth of atherosclerotic plaque, and slightly lower arterial blood pressure $(6,20,29)$.

Interventional techniques, specifically cervical epidural injections, may be associated with increased risk of bleeding, resulting in an occasional epidural hematoma (30-45). The present guidelines do not recommend discontinuation of low dose aspirin or discontinuation of antiplatelet therapy based on the risk-benefit ratio $(30,31,44,45)$. Further, there is no guidance available on omega- 3 fatty acids and discontinuation of fish oil prior to high risk interventional techniques including cervical epidural injections.

Consequently, there is a potential for bleeding complications with interventional techniques in patients on fish oil with or without concomitant administration of aspirin or other antiplatelet therapeutic agents. We provide a case report of a patient on fish oil developing an epidural hematoma after administration of an uneventful cervical epidural injection under fluoroscopic guidance.

\section{CASE REPORT}

A 49-year-old woman with a history of moderate spinal stenosis in the cervical area presented to our pain center for routine cervical epidural injection for neck and shoulder pain. Two years prior, she had an anterior cervical disc fusion at C5-C6 for significant
C6 radiculopathy and had subsequently developed disc herniations above and below the level of fusion. She had undergone 3 prior cervical epidural steroid injections at our center after her fusion while taking $81 \mathrm{mg}$ aspirin without any bleeding complications. However, since her last epidural, it was discovered that she had been taking over-the-counter fish oil $2400 \mathrm{mg}$ daily, along with her daily aspirin intake.

The patient was placed in a prone position and, under fluoroscopic guidance in the posteroanterior (PA) and lateral position, a \#18 Rx Coude needle was used to locate the C7-T1 epidural space using the loss of resistance technique. No parenthesis, cerebrospinal fluid (CSF), or blood was noted, and the final position of the needle was confirmed by injection of $2 \mathrm{~mL}$ Omnipaque 240 in real-time fluoroscopy. There was good spread of contrast above and below the levels of fusion, and no intravascular or intrathecal dye diffusion was noted (Fig. 1). Upon confirmation of correct needle placement, $3 \mathrm{~mL}$ of a preservative-free saline solution containing $12 \mathrm{mg}$ Celestone Soluspan was injected without any problems. The procedure was successful and without any immediate complication. She was discharged home $\mathbf{2 0}$ minutes later in stable condition.

When she arrived at home, approximately $40 \mathrm{~min}$ utes after her procedure, she experienced numbness and tingling in both arms and significant pain between her shoulder blades. Within 30 minutes of her symptom onset, she was sent to the emergency room and while in the magnetic resonance imaging (MRI) scanner, developed a left-sided wrist drop. A cervical MRI showed a $7 \mathrm{~mm}$ epidural hemorrhage extending superiorly to the C2-C3 level and inferiorly to the T4 level (Fig. 2). The majority of the hemorrhage was at the C6-C7 level associated with moderate cervical stenosis due to a cervical disc herniation at that same level (Fig. 3). She underwent emergent surgical decompression and evacuation of the hematoma through multiple laminectomies at C6, C7, and T1. The surgeon noticed excessive blood oozing through the incision site and left 2 drains in the wound. Postoperatively, she had immediate relief of her symptoms and regained her wrist strength. Postoperative imaging was not obtained due to her exceptional clinical progress, and she was discharged home 3 days later without any measurable deficit. 


\section{DISCUSSION}

We provided a case report of an uneventful cervical epidural injection resulting in cervical epidural hematoma with appropriate decompression with no residual dysfunction.

The literature search yielded multiple case reports of cervical epidural hematoma following cervical epidural injections $(33-36,38-40)$. One of the case reports showed chronic subdural hematoma developing after one month (33). The majority of the other 3 cases $(34-36,38-40)$ reported cervical epidural hematoma with epidural injections requiring surgical decompressions. In one case report, the potential contributing effect of ketorolac and fluoxetine was discussed (36). There are no published reports of cervical epidural hematoma in patients receiving antiplatelet therapy or supplements such as fish oil. The prevalence statistics of epidural hematoma in the cervical spine are unknown even though a rate of 1.38 in 10,000 to 1 in 250,000 epidural procedures has been reported (36). Interlaminar epidural injections are frequent. Utilization data in the Medicare population showed 419 cervical and thoracic epidural injections were performed per 100,000 Medicare fee-for-service (FFS) population in 2013 (7). Large case series of cervical epidural injections reported no associated serious neurological complications including epidural hematoma (43). In a meta-analysis with inclusion of relevant literature, 8 cases of neuraxial hematoma following epidural injections were identified with involvement of 4 cases in the cervical spine and 4 cases in the thoracic and lumbar spine (37). The published data from the American Society of Anesthesiologists Closed Claims Project showed that between 1970 and 2000, there were 6 claims for paraplegia or quadriplegia due to epidural hematoma resulting from an interventional pain management procedure (41). In addition, 3 cases of compressive epidural hematoma due to cervical injections were also reported with review of the data between 2005 and 2008 (42). However, these estimations may not provide the appropriate prevalence of cervical epidural hematoma related to epidural injections.

Multiple mechanisms have been described for development of epidural hematoma basically related to epidural venous and arterial bleeding or bleeding from arterial venous malformations. The posterior internal vertebral venous plexus has been proposed as the most likely source of bleeding (46). However, others have argued that due to differential pressures with venous pressure being less than intrathecal pressure, venous bleeding may not be capable of causing acute spinal cord compression. In support of the arterial origin of epidural hematoma, 3 cases 


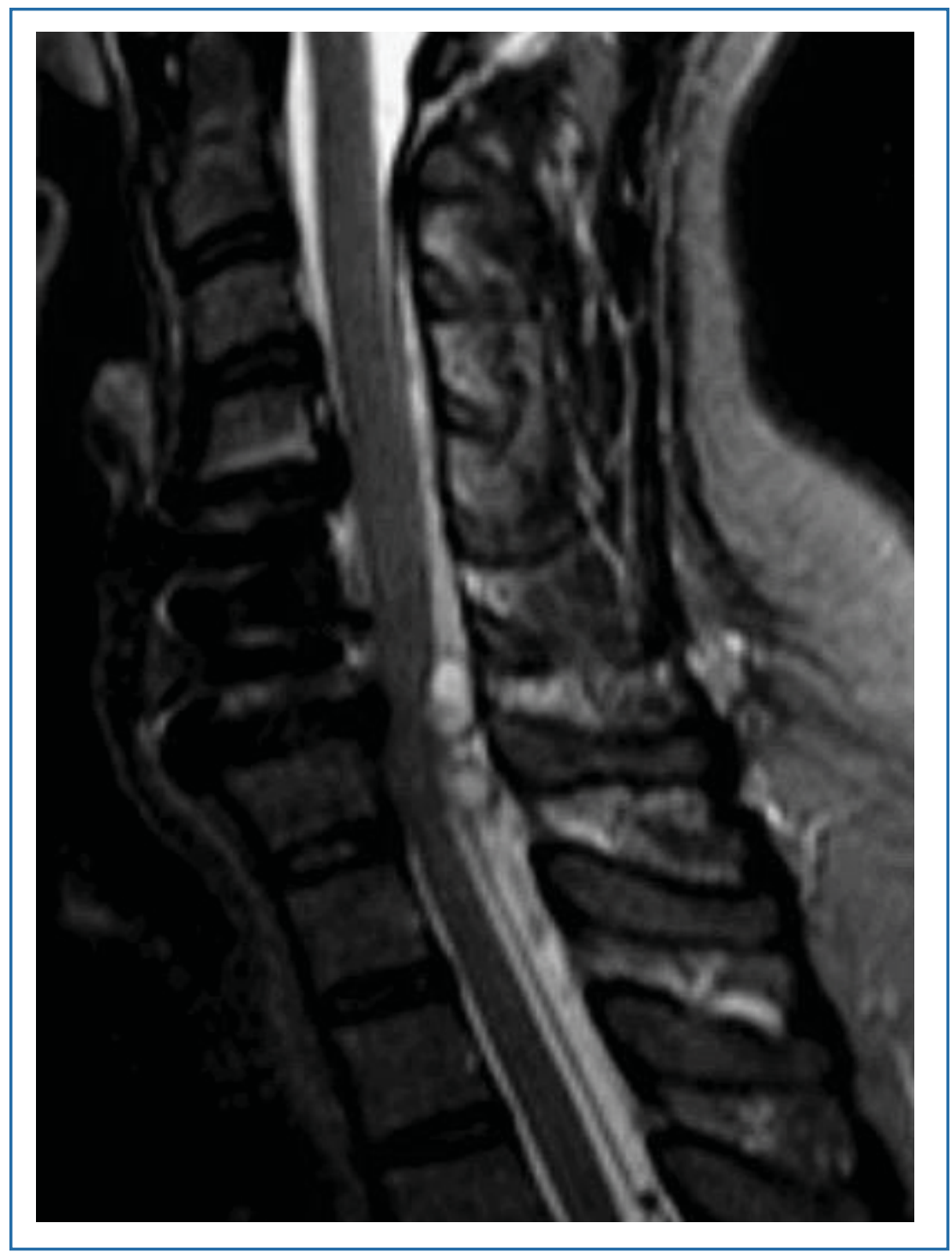

Fig. 2. Cervical MRI, STIR sagittal view. Epidural hematoma C6-C7. of the cases reported in the literature (30\%) were idiopathic or spontaneous, $17 \%$ were related to anticoagulation, and $10 \%$ were related to spinal or epidural anesthesia (52). The majority of the cases have been reported due to continuous epidurals in anticoagulated patients or with thrombocytopenic disorders $(53,54)$. Among the multiple cases reported, association with aspirin or other non-steroidal anti-inflammatory drugs (NSAIDs) was reported in 3 cases, low molecular weight heparin was included in 2 cases, and fibrinolytic therapy in 2 cases. However, these are not all related to cervical epidural injections.

The cervical spinal cord is the most vulnerable to compression given the relatively smaller diameter of the spinal canal including a smaller peridural space in this area compared to thoracic and lumbar levels (55). A wide anatomic variation also has been reported with arterial distribution in the cervical spine, which may increase such risk (56). Other risk factors include advanced age, chronic renal insufficiency, female gender, and spinal stenosis and spondylolysis.

In consideration of the medication risk factors, fish oil may be have been reported showing the bleeding arising from arteries in the posterior longitudinal ligament following anterior discectomy (47).

Multiple risk factors have been reported as a cause of cervical epidural hematoma including anticoagulation medication usage, anatomic abnormalities of the vertebral column, difficult or repeated epidural punctures, older age, intrinsic thrombocytopenia or platelet dysfunction, renal failure, and coagulopathy related to hemophilia (48-52). Further, the majority one of the risk factors, while modern guidance describes continuation of aspirin and some antiplatelet therapy in almost all cases, whereas in others, a risk benefit assessment must be performed prior to discontinuation of these drugs $(30,31,39)$.

Fish oils have been demonstrated to impair hemostasis. The effects have been attributed to the bioactive ingredients docosahexaenoic acid (DHA) and eicosapentaenoic acid (EPA). The hemostatic properties reported include a hypocoagulant effect (57), 
reduction in vitroplatelet aggregation (57), and prolongation of bleeding time in humans $(57,58)$. Further, these effects are augmented for fish oil in combination with antiplatelet or antithrombotic therapy (57). However, these effects have not been demonstrated to have any clinically significant impact on bleeding, even in patients being treated with antiplatelet or antithrombotic agents (58). Multiple evaluations assessing the potential role of excessive bleeding (21-28) have yielded variable results with all of them concluding that there is no significant impact on bleeding during surgery or other procedures. Fish oil has been recommended as prophylactic therapy to prevent cardiovascular disorders by the AHA and others $(59,60)$.

Omega-3 fatty acids are found in seafood, nuts, and

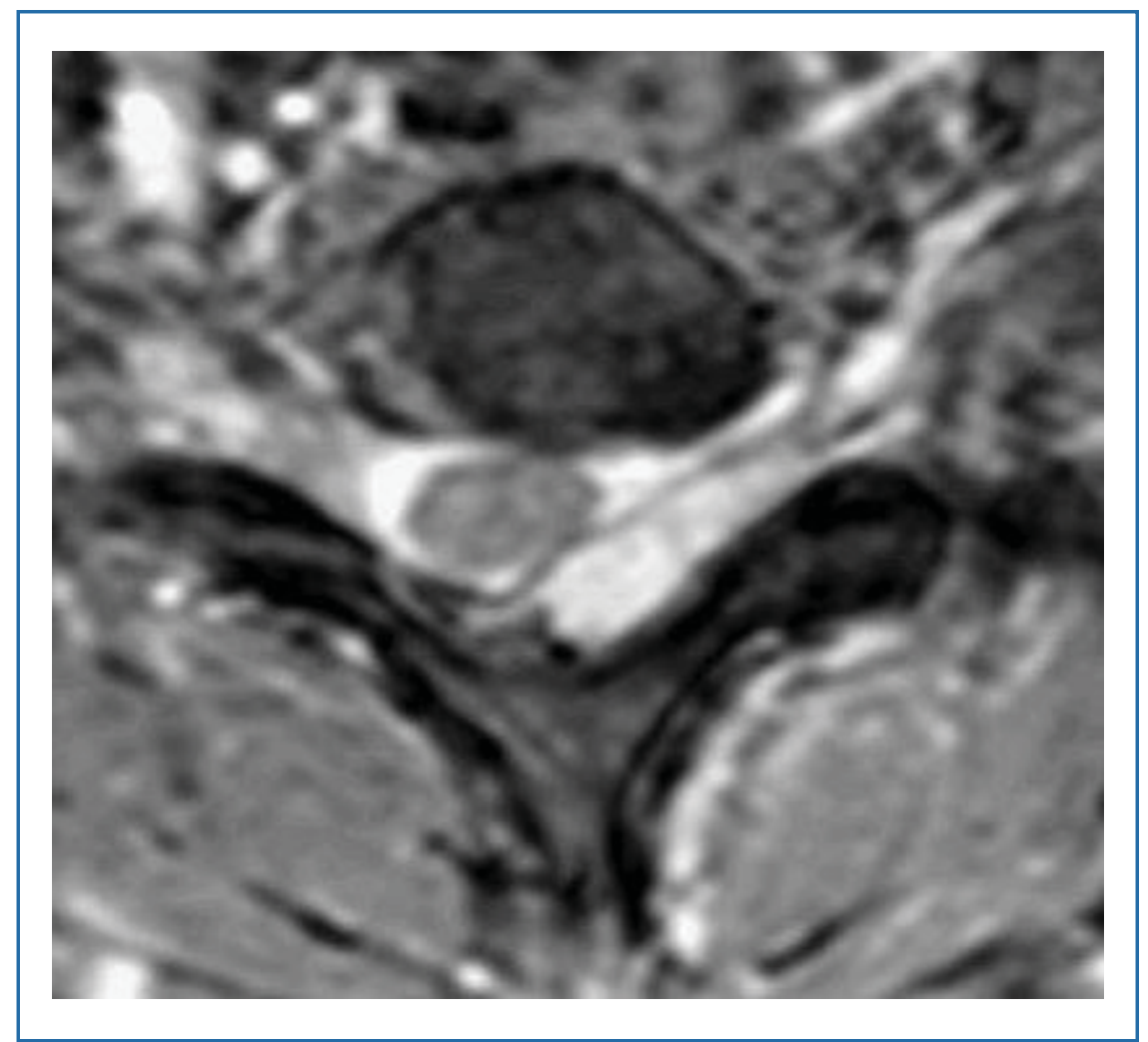

Fig. 3. Cervical MRI, T2 axial view. Epidural hematoma C6-C7 compressing on left cord. plant oils. Fish and fish oil contain 20-carbon EPA and 22-carbon DHA, which are the most researched compounds. However, canola and flaxseed oils, walnuts, and soybeans contain 18-carbon $\alpha$-linolenic acid (ALA), which has been less researched and is speculated to be a less clinically significant compound. Studies reveal that omega-3 fatty acids reduce plasma triglycerides and VLDL lipids, raise HDL levels, and have an anticoagulant effect and antithrombotic potential at sufficient doses. The mechanism involves incorporation of EPA and DHA into the platelet membrane, reducing platelet aggregation. EPA and DHA build up in plasma leading to lasting effects on platelet aggregation for at least 4 weeks. A synergistic antiplatelet effect with aspirin has also been demonstrated when fatty acids are at higher levels (61). Despite these findings, one study concluded that there was no increased risk of bleeding when fish oil was added to an antiplatelet regimen of aspirin and clopidogrel. There remains a paucity of related literature about fish oil complications and

no studies have demonstrated definitive evidence related to increased risk of bleeding.

Interest in fish oils stems largely from a study published in 1970 showing that Greenland Eskimos had a low rate of ischemic heart disease despite their high fat diet consisting mainly of fish (22). Numerous studies have been performed since then linking fish intake with reduction in risks of cardiovascular disease. In fact, in 2008, it was recommended that all clinicians should strongly consider therapy with fish oil (17). In addition, the AHA in 2002 recommended that dietary consumption should be increased to at least 2 fatty fishes per week with the addition of vegetable oils, as well as nuts and seeds (18). While the AHA continues to recommend daily intake of fish oil, global guidelines also emphasize these recommendations $(19,20)$.

Even though the recommendations are overwhelming and as many as one-third of Americans consume these supplements, the literature showing the ben- 
efits, as well as associated risks, are inconclusive. A systematic review (59) concluded that fish oil use has not been supported by research after summarizing the results from 18 randomized controlled trials (RCTs) and 6 meta-analyses of RCTs published in high profile journals. Based on this review, it appears that the benefit from fish oil was reported in only 2 studies, leading the authors to conclude sales of fish oil have increased despite unsupported claims. However, multiple other trials and systematic reviews have supported their use with some evidence. Considering side effects rather than benefits, which may outweigh the benefits, risk of bleeding has been an issue of concern for surgeons, as well as interventional pain physicians (22-28). The literature concerning the bleeding risk is also controversial with some showing increased risk, some showing lack of increased risk, and others showing that despite the alteration in the anticoagulation mechanism, the risks are negligible.

Proponents show that the principle difference between the older and the more recent $n-3$ studies was a greater use of background optimal medical therapy that may have reduced the benefit from $n-3$. Additionally, they also stated that some of the more recent trials used relatively low doses or tested $n-3$ supplementation on top of a relatively high baseline intake of $n-3 s$ (60). However, fish oil administration is also associated with multiple side effects. Even though the Food and Drug Administration (FDA) does not generally regulate fish oil supplements, a few producers of fish oil have chosen to have their product evaluated by the United States Pharmacopeia (USP) (58). It has been shown that many fish oil supplements contain vitamin $E$, which has been found to increase the risk of hemorrhagic stroke, thus increasing the anticoagulant effects of fish oil in combination with vitamin $\mathrm{E}$ and when taken in conjunction with aspirin (61). Further, fish oil consumption may have different effects depending on which formulation is taken and whether the patient is on antiplatelet therapy.

Considering the variability of fish oil concentrations and frequent use of antiplatelet medication in the general population, there are now concerns for elevated bleeding risk related to interventional procedures. However, fish oil is not routinely discontinued for interventional procedures, and some have even suggested that it does not actually increase the risk of bleeding. At this time, there are no established guidelines for fish oil use pertaining to interventional techniques. Additionally, there is only limited evidence to discontinue antiplatelet therapy with platelet aggregation inhibitors to avoid bleeding and epidural hematomas, and a recent meta-analysis of evidence, actually suggested continuation of NSAIDs, low dose aspirin, and phosphodiesterase inhibitors during interventional techniques (30).

In our case, the patient had 3 prior cervical epidural steroid injections while taking low dose aspirin without any bleeding complication. This demonstrates the effectiveness of the current safety guidelines for continuing antiplatelet therapy for interventional procedures. However, at the time of her last epidural steroid injection that resulted in a bleeding complication, 2,400 mg of fish oil had been added to her daily regimen of low dose aspirin. Concomitant use of aspirin and fish oil likely produced a synergistic effect, which increased her risk of developing cervical epidural hematoma.

\section{CONCLUSION}

Fish oil may predispose a patient to bleeding complications when used in higher doses alone or when used at any dose in conjunction with antiplatelet use. Practitioners must be aware of bleeding risks, clinical presentation with bleeding and formation of hematoma associated with severe and unusual pain at the site of injection and contribution of loss of resistance technique with air, and the longer-term preventative health benefits of fish oil use should be weighed against the potential immediate risk of bleeding after interventional techniques are performed.

\section{DISCLAIMER}

All authors have no conflicts of interest to report. None of the authors of the manuscript received remuneration, reimbursement, or honorarium in any manner. There was no external funding in the preparation of this manuscript. Conflict of interest: Each author certifies that he or she, or a member of his or her immediate family, has no commercial association (i.e., consultancies, stock ownership, equity interest, patent/licensing arrangements, etc.) that might pose a conflict of interest in connection with the submitted manuscript. 
Fish Oil as a Potential Contributor to Epidural Hematoma

\section{REFERENCES}

1. Mozaffarian D, Benjamin EJ, Go AS, Arnett DK, Blaha MJ, Cushman M, Das SR, de Ferranti S, Després JP, Fullerton HJ, Howard VJ, Huffman MD, Isasi CR, Jiménez MC, Judd SE, Kissela BM, Lichtman JH, Lisabeth LD, Liu S, Mackey RH, Magid DJ, McGuire DK, Mohler ER 3rd, Moy CS, Muntner P, Mussolino ME, Nasir K, Neumar RW, Nichol G, Palaniappan L, Pandey DK, Reeves MJ, Rodriguez CJ, Rosamond W, Sorlie PD, Stein J, Towfighi A, Turan TN, Virani SS, Woo D, Yeh RW, Turner MB; American Heart Association Statistics Committee and Stroke Statistics Subcommittee. Heart Disease and Stroke Statistics-2016 Update: A report from the American Heart Association. Circulation 2016; 133:e38-e360.

2. US Burden of Disease Collaborators. The state of US health, 1999-2010: Burden of diseases, injuries, and risk factors. JAMA 2013; 310:591-608.

3. Manchikanti L, Singh V, Falco FJE, Benyamin RM, Hirsch JA. Epidemiology of low back pain in adults. Neuromodulation 2014; 17:3-10.

4. Kakoti BB, Hernandez-Ontiveros DG, Kataki MS, Shah K, Pathak Y, Panguluri SK. Resveratrol and omega-3 fatty acid: Its implications in cardiovascular diseases. Front Cardiovasc Med 2015; 2:38.

5. Nestel P, Clifton P, Colquhoun D, Noakes M, Mori TA, Sullivan D, Thomas B. Indications for omega-3 long chain polyunsaturated fatty acid in the prevention and treatment of cardiovascular disease._Heart Lung Circ 2015; 24:769-779.

6. DiNicolantonio JJ, Niazi AK, McCarty MF, O'Keefe JH, Meier $\mathrm{P}$, Lavie CJ. Omega-3s and cardiovascular health. Ochsner J 2014; 14:399-412.

7. Manchikanti L, Pampati V, Falco FJE, Hirsch JA. An updated assessment of utilization of interventional pain management techniques in the Medicare population: 2000 - 2013. Pain Physician 2015; 18:E115-E127.

8. Manchikanti L, Nampiaparampil DE, Candido KD, Bakshi S, Grider JS, Falco FJE, Sehgal N, Hirsch JA. Do cervical epidural injections provide long-term relief in neck and upper extremity pain? A systematic review. Pain Physician 2015; 18:39-60.

9. Manchikanti L, Kaye AD, Manchikanti KN, Boswell MV, Pampati $V$, Hirsch JA. Efficacy of epidural injections in the treatment of lumbar central spinal stenosis: A systematic review. Anesth Pain Med 2015; 5:e23139.

10. Manchikanti L, Benyamin RM, Falco FJ, Kaye AD, Hirsch JA. Do epidural injections provide short- and long-term relief for lumbar disc herniation? A systematic review. Clin Orthop Relat Res 2015; 473:1940-1956.

11. Manchikanti L, Nampiaparampil DE, Manchikanti KN, Falco FJE, Singh V, Benyamin RM, Kaye AD, Sehgal N, Soin A, Simopoulos TT, Bakshi S, Gharibo CG, Gilligan CJ, Hirsch JA. Comparison of the efficacy of saline, local anesthetics, and steroids in epidural and facet joint injections for the management of spinal pain: A systematic review of randomized controlled trials. Surg Neurol Int 2015; 6:S194-S235

12. Manchikanti L, Knezevic NN, Boswell MV, Kaye AD, Hirsch JA. Epidural injections for lumbar radiculopathy and spinal stenosis: A comparative systematic review and meta-analysis. Pain Physician 2016; 19:E365-E410.

13. Manchikanti L, Helm S II, Pampati V, Racz GB. Cost utility analysis of percutaneous adhesiolysis in managing pain of post-lumbar surgery syndrome and lumbar central spinal stenosis. Pain Pract 2015; 15:414-422.

14. Manchikanti L, Falco FJE, Pampati V, Cash KA, Benyamin RM,
Hirsch JA. Cost utility analysis of caudal epidural injections in the treatment of lumbar disc herniation, axial or discogenic low back pain, central spinal stenosis, and post lumbar surgery syndrome. Pain Physician 2013; 16:E129-E143.

15. Lewis R, Williams N, Matar HE, Din N, Fitzsimmons D, Phillips C, Jones M, Sutton A, Burton K, Nafees S, Hendry M, Rickard I, Chakraverty $\mathrm{R}$, Wilkinson $\mathrm{C}$. The clinical effectiveness and costeffectiveness of management strategies for sciatica: Systematic review and economic model. Health Technol Assess 2011; 15:1578.

16. Lewis RA, Williams NH, Sutton AJ, Burton K, Din NU, Matar HE, Hendry M, Phillips CJ, Nafees S, Fitzsimmons D, Rickard I, Wilkinson C. Comparative clinical effectiveness of management strategies for sciatica: Systematic review and network meta-analyses. Spine J 2015; 15:1461-1477.

17. Artham SM, Lavie CJ, Milani RV, Anand RG, O'Keefe JH, Ventura $\mathrm{HO}$. Fish oil in primary and secondary cardiovascular prevention. Ochsner J 2008; 8:49-60.

18. Kris-Etherton PM, Harris WS, Appel LJ. Fish Consumption, fish oil, omega-3 fatty acids, and cardiovascular disease. Circulation 2002; 106:2747-2757.

19. Global Organization for EPA and DHA Omega-3 (GOED), Global Recommendations for EPA and DHA Intake (Rev 16 April 2014)

www.goedomega3.com/index.php/files/download/304.

20. American Heart Association. Fish and Omega-3 Fatty Acids. www.heart.org/HEARTORG/HealthyLiving/HealthyEating/HealthyDietGoals/Fish-and-Omega-3-Fatty-Acids UCM 303248 Article.jsp\#.VvrRv-90zcs

21. Dyerberg J, Bang HO, Stoffersen E, Moncada S, Vane JR. Eicosapentaenoic acid and prevention of thrombosis and atherosclerosis? Lancet 1978; 2:117-119.

22. Andersen MR, Sweet E, Zhou M, Standish LJ. Complementary and alternative medicine use by breast cancer patients at time of surgery which increases the potential for excessive bleeding. Integr Cancer Ther 2015; 14:119-124.

23. Detopoulou P, Papamikos V. Gastrointestinal bleeding after high intake of omega-3 fatty acids, cortisone and antibiotic therapy: A case study. Int J Sport Nutr Exerc Metab 2014; 24:253-257.

24. Wachira JK, Larson MK, Harris WS. N-3 fatty acids affect haemostasis but do not increase the risk of bleeding: Clinical observations and mechanistic insights. Br J Nutr 2014; 111:16521662.

25. Villani AM, Crotty M, Cleland LG, James MJ, Fraser RJ, Cobiac L, Miller MD. Fish oil administration in older adults with cardiovascular disease or cardiovascular risk factors: Is there potential for adverse events? A systematic review of the literature. Int J Cardiol 2013; 168:4371-4375.

26. Meredith DS, Kepler CK, Huang RC, Hirsch B, Nguyen J, Farmer JC, Girardi FP, O'Leary PF, Cammisa FP. The effect of omega-3 fatty-acid supplements on perioperative bleeding following posterior spinal arthrodesis. Eur Spine J 2012; 21:2659-2663.

27. Kepler CK, Huang RC, Meredith D, Kim JH, Sharma AK. Omega-3 and fish oil supplements do not cause increased bleeding during spinal decompression surgery. J Spinal Disord Tech 2012; 25:129-132.

28. Stanger MJ, Thompson LA, Young AJ, Lieberman HR. Anticoagulant activity of select dietary supplements. Nutr Rev 2012; 70:107-117.

29. Whoriskey P. Fish oil pills: A $\$ 1.2$ billion industry built, so far, on 
empty promises. The Washington Post, July 18, 2015 www.washingtonpost.com/business/economy/claims-thatfish-oil-boosts-health-linger-despite-science-saying-the-opposite/2015/07/08/db7567d2-1848-11e5-bd7f-4611a60dd8e5 story.html

30. Manchikanti L, Falco FJE, Benyamin RM, Caraway DL, Kaye AD, Helm II S, Wargo BW, Hansen H, Parr AT, Singh V, Swicegood JR, Smith HS, Schultz DM, Malla Y, Hirsch JA. Assessment of bleeding risk of interventional techniques: A best evidence synthesis of practice patterns and perioperative management of anticoagulant and antithrombotic therapy. Pain Physician 2013; 16:SE261-SE318.

31. Manchikanti L, Malla Y, Wargo BW, Cash KA, McManus CD, Damron KS, Jackson SD, Pampati V, Fellows B. A prospective evaluation of bleeding risk of interventional techniques in chronic pain. Pain Physician 2011; 14:317-329

32. Manchikanti L, Hirsch JA. Neurological complications associated with epidural steroid injections. Curr Pain Headache Rep 2015; $19: 482$.

33. Kim M, Park KS. Intracranial chronic subdural hematoma presenting with intractable headache after cervical epidural steroid injection. J Korean Neurosurg Soc 2015; 58:144-146.

34. Reitman CA, Watters W 3rd. Subdural hematoma after cervical epidural steroid injection. Spine (Phila Pa 1976) 2002; 27:E174E176.

35. Williams KN, Jackowski A, Evans PJ. Epidural haematoma requiring surgical decompression following repeated cervical epidural steroid injections for chronic pain. Pain 1990; 42:197-199.

36. Chien GC, McCormick Z, Araujo M, Candido KD. The potential contributing effect of ketorolac and fluoxetine to a spinal epidural hematoma following a cervical interlaminar epidural steroid injection: A case report and narrative review. Pain Physician 2014; 17:E385-E395.

37. Xu R, Bydon M, Gokaslan ZL, Wolinsky JP, Witham TF, Bydon A. Epidural steroid injection resulting in epidural hematoma in a patient despite strict adherence to anticoagulation guidelines. $J$ Neurosurg Spine 2009; 11:358-364.

38. Benyamin RM, Vallejo R, Wang V, Kumar N, Cedeño DL, Tamrazi $A$. Acute epidural hematoma formation in cervical spine after interlaminar epidural steroid injection despite discontinuation of clopidogrel. Reg Anesth Pain Med 2016; 41:398-401.

39. Manchikanti L, Malla Y, Benyamin RM, Hirsch JA. Prevalence of epidural hematoma following cervical epidural injections in interventional pain management settings: Literature review with two case reports. IPM Reports 2017; 11-17.

40. Swicegood JR, Manchikanti L, Benyamin RM, Hirsch JA. Two cases of acute epidural hematoma formation after cervical interlaminar epidural steroid injections. IPM Reports 2017; 1:27-32.

41. Fitzgibbon DR. Chronic pain management: ASA closed claims project. Anesthesiology 2004; 100:98-105.

42. Rathmell JP, Michna E, Fitzgibbon DR, Stephens LS, Posner $\mathrm{KL}$, Domino KB. Injury and liability associated with cervical procedures for chronic pain. Anesthesiology 2011; 114:918-926.

43. Manchikanti L, Malla Y, Wargo BW, Cash KA, Pampati V, Fellows B. A prospective evaluation of complications of 10,000 fluoroscopically directed epidural injections. Pain Physician 2012; 15:131-140.

44. Bogduk N (ed). Practice Guidelines for Spinal Diagnostic and Treatment Procedures. 2nd edition. International Spine Intervention Society (ISIS), San Francisco, 2013.

45. Narouze S, Benzon HT, Provenzano DA, Buvanendran A, De Andres J, Deer TR, Rauck R, Huntoon MA. Interventional spine and pain procedures in patients on antiplatelet and anticoagulant medications: Guidelines from the American Society of Regional Anesthesia and Pain Medicine, the European Society of Regional Anaesthesia and Pain Therapy, the American Academy of Pain Medicine, the International Neuromodulation Society, the North American Neuromodulation Society, and the World Institute of Pain. Reg Anesth Pain Med 2015; 40:182-212.

46. Groen RJ, Ponssen H. The spontaneous spinal epidural hematoma. A study of the etiology. J Neurol Sci 1990; 98:121-138.

47. U HS, Wilson CB. Postoperative epidural hematoma as a complication of anterior cervical discectomy. Report of three cases. J Neurosurg 1978; 49:288-291.

48. Horlocker TT, Wedel DJ. Neuraxial block and low-molecular weight-heparin: Balancing perioperative analgesia and thromboprophylaxis. Reg Anesth Pain Med 1998; 23:164-177.

49. Yoo HS, Park SW, Han JH, Chung JY, Yi JW, Kang JM, Lee BJ, Kim DO. Paraplegia caused by an epidural hematoma in a patient with unrecognized chronic idiopathic thrombocytopenic purpura following an epidural steroid injection. Spine 2009; 34:E376-E379.

50. Takahashi K, Koewa F, Tayama H, Satomi A, Akizawa T, Ideura $\mathrm{T}$. A case of acute spontaneous epidural haematoma in a chronic renal failure patient undergoing haemodialysis: Successful outcomes with surgical management. Nephrol Dial Transplant 1999; 14:2499-2501.

51. Yokota S, Hirabayashi Y, Wakata M, Maruyama Y, Mukoyama A, Nomura M, Hamada S, Ijichi N, Matsumoto T, Shima M. Mild hemophilia A diagnosed at the onset of acute epidural hematoma after lumbar epidural block. Rinsho Ketsueki 2011; 52:78-83.

52. Kreppel D, Antoniadis G, Seeling W. Spinal hematoma: A literature survey with meta-analysis of 613 patients. Neuorsurg Rev 2003; 26:1-49.

53. Vandermeulen EP, Van Aken H, Vermylen J. Anticoagulants and spinal-epidural anesthesia. Anesth Analg 1994; 79:1165-1177.

54. Wulf H. Epidural anesthesia and spinal haematoma. Can J Anaesth 1996; 42:1260-1273.

55. Stoll A, Sanchez M. Epidural hematoma after epidural block: Implications for its use in pain management. Surg Neurol 2002; 57:235-240.

56. Huntoon MA. Anatomy of the cervical intervertebral foramina: Vulnerable arteries and ischemic neurologic injuries after transforaminal epidural injections. Pain 2005; 117:104-111.

57. Svaneborg N. Kristensen SD, Hansen LM, Büllow I, Husted SE, Schmidt EB. The acute and short-time effect of supplementation with the combination of $n-3$ fatty acids and acetylsalicylic acid on platelet function and plasma lipids. Thromb Res 2002; 105:311316.

58. Bays HE. Safety considerations with omega-3 fatty acid therapy. Am J Cardiol 2007; 99:35C-43C

59. Grey A, Bolland M. Clinical trial evidence and use of fish oil supplements. JAMA Intern Med 2014; 174:460-462.

60. DiNicolantonio JJ, Niazi AK, O'Keefe JH, Lavie CJ. Explaining the recent fish oil trial "failures." J Glycomics Lipidomics 2013; 3:e112.

61. Block RC, Kakinami L, Jonovich M, Antonetti I, Lawrence P, Meednu N, CalderonArtero P, Mousa SA, Brenna JT, Georas $S$. The combination of EPA+DHA and low-dose aspirin ingestion reduces platelet function acutely whereas each alone may not in healthy humans. Prostaglandins Leukot Essent Fatty Acids 2012; 87:143-151. 